\title{
Real Time Ultrasound Elastography for the Differentiation of Benign and Malignant Thyroid Nodules
}

\author{
Hamad Elniel H. Eltyib, Ibrahim A. Awad, Naglaa M. Elsayed, Saddig D. Jastaniah \\ Department of Diagnostic Radiology, Faculty of Applied Medical Sciences, King Abdulaziz University, \\ Jeddah, KSA \\ Email: haltyeb@kau.edu.sa
}

Received 26 November 2013; revised 26 December 2013; accepted 2 January 2014

Copyright (C) 2014 by authors and Scientific Research Publishing Inc.

This work is licensed under the Creative Commons Attribution International License (CC BY). http://creativecommons.org/licenses/by/4.0/

(c) (i) Open Access

\section{Abstract}

The purpose of this study was to evaluate the predictive value of real-time ultrasound elastography (RUE) in differentiating benign from malignant thyroid nodules, with fine needle aspiration cytology analysis as the reference standard. A total of 78 consecutive patients with thyroid nodules who were selected for fine needle aspiration biopsies were examined in this prospective study. 78 nodules in these patients were examined by conventional ultrasound, and ultrasound elastography. The final diagnosis was obtained from cytological findings. Tissue stiffness on ultrasound elastography was scored from 1 (low stiffness over the entire nodule) to 5 (high stiffness over the entire nodule and surrounding tissue). On real-time ultrasound elastography, 47 of 62 benign nodules (76\%) had a score of 1 or 2 , whereas 15 of 16 malignant nodules had a score of 3 to 5 , with sensitivity of $93.7 \%$, specificity of $90 \%$, a positive predictive value of $71 \%$, and a negative predictive value of $98 \%$. Real-time ultrasound elastography is a promising imaging technique that is useful in the differential diagnosis of thyroid cancer. Utilization of ultrasound elastography could reduce the rate of thyroid biopsies because of its high elasticity being highly associated with benign cytology.

\section{Keywords}

Elastography; Real-Time; Thyroid Nodules; Ultrasound; Malignant

\section{Introduction}

Nodular thyroid disease is a common finding in the general population, in particular in iodine-deficient areas.

How to cite this paper: Eltyib, H.E.H., Awad, I.A., Elsayed, N.M. and Jastaniah, S.D. (2014) Real Time Ultrasound Elastography for the Differentiation of Benign and Malignant Thyroid Nodules. Open Journal of Medical Imaging, 4, 38-47. http://dx.doi.org/10.4236/ojmi.2014.41006 
Thyroid nodules are palpable in 5\% of subjects [1] [2] but are detectable by thyroid ultrasound (US) in up to $50 \%$ of the general population [3]-[5]. Only a minority of thyroid nodules are likely to cause significant health problems. Cytological examination of material obtained by fineneedle aspiration (FNAC), due to its high sensitivity and specificity, is the best single test for differentiating malignant from benign thyroid lesions [6]. The major limitation of FNA cytology is that $10 \%$ to $15 \%$ of specimens are nondiagnostic [7], and $10 \%$ to $20 \%$ are indeterminate [8]-[10].

Thyroid nodules are a common medical problem [7]. Although they are traditionally found as palpable masses at neck examination in patients with or without suspected thyroid disease, the apparent prevalence of non-palpable thyroid nodules (i.e. $<1 \mathrm{~cm}$ in diameter) in the general population has recently increased, probably as a consequence of the increasing application of ultrasound [8] [11].

Revised American Thyroid Association Management Guidelines for Patients with Thyroid Nodules and Differentiated Thyroid Cancer (Recommendation 4-A7): FNA is the most accurate and cost-effective method for evaluating thyroid nodules. Retrospective studies have reported lower rates of both nondiagnostic and falsenegative cytology specimens from FNA procedures performed via US guidance compared to palpation [12] [13].

Conventional ultrasound does not provide direct information corresponding to the hardness of a nodule. Elastography is a newly developed dynamic technique that uses US to provide an estimation of tissue stiffness by measuring the degree of distortion under the application of an external force. US elastography has been applied to study the hardness/elasticity of nodules to differentiate malignant from benign lesions [14]-[17]. The thyroid gland is well positioned for elastographic examination: It is easily assessable and can be efficiently compressed against underlying anatomic structures by using a US probe [18]. Tanaka et al. [19] showed sensitivity of 89.1\% and specificity of $59.4 \%$. Rago et al. [20] reported sensitivity of $97 \%$ and specificity of $100 \%$ for this technique.

The elasticity scoring system initially proposed by Ueno and Itoh [21] was useful for comparing breast ultrasound elastographic results , but later modified for thyroid nodules by Rago and Asteria [20] [22].

We aimed to evaluate the diagnostic utility of realtime ultrasound elastography in differentiating benign from malignant thyroid nodules.

\section{Materials and Methods}

\subsection{Patients}

Between March 2012 and November 2013, a prospective evaluation was performed in 100 patients with thyroid nodules referred to ultrasound division at the diagnostic radiology department, at King Abdulaziz University Hospital. The patients (88 women, 12 men; age range, 19 - 80 years; mean age, 43 years) who were examined for conventional ultrasound and real-time elastography, and the final diagnosis was based on the results of cytological evaluation. Ethical approval from the medical research of our university, and informed consent was obtained from all patients.

\subsection{Conventional Ultrasound and Ultrasound Elastography}

After obtaining verbal consent from patients, Ultrasound examination was done by an expert sonographer and radiologist following a standard protocol. Patients were examined by skilled staff sonographers and then re-examined by more than three radiologists to confirm all findings for each patient, data recorded on a work sheet before patient leaving the ultrasound department. Both conventional ultrasound imaging and real-time ultrasound elastography were performed using a Philips IU22 system equipped with a high-frequency linear array transducer of $5 \mathrm{MHz}$ to $12 \mathrm{MHz}$. The examination was done with the patients lying supine with their necks hyper extended.

For all patients, the ultrasound examination started with B-mode imaging. Images of each lobe were obtained in transverse and longitudinal with the probe was placed gently on the thyroid of a patient in the supine position in both transverse and longitudinal orientation. For interpretation of the conventional ultrasound, all the ultrasound characteristic features performed on all thyroid nodules: (e.g. echogenicity; calcifications, margins, and the presence and pattern of blood flow on color Doppler flow) had been considered for evaluation of the nodules.

By using the same real-time instrument and the same transducer ultrasound elastographic was performed. The transducer was placed on the neck with light pressure, and a box was highlighted by the operator, which in- 
cluded the nodule and sufficient surrounding thyroid tissue to be evaluated. The principal of ultrasound elastography is to obtain 2 ultrasound images before and after external pressure of thyroid tissue by the transducer through the adapter and track displacement tissues, through the assessment of the spread of the imaging beam.

The ultrasound elastogram was displayed over the B-mode image in a color scale that ranged from red for components with the greatest elastic strain (i.e., softest components) to blue for those with no strain (i.e., hardest components) (Figure 1).

Tissue stiffness on ultrasound elastography was scored (ES) from 1 (greatest elastic strain) to 5 (no strain) based on subjective analysis of the elastogram image. The scoring was classified by Ei Ueno and Itoh (2006) to differentiate benign and malignant lesions and is based on color pattern with elastography [21] (Table 1).

\subsection{Biopsy Method and Pathologic Correlation}

The 100 patients were selected for the FNAC according to their previous conventional ultrasound results which recommended or suggested for FNA by the radiologists.

All thyroid nodule biopsies (FNAC) were performed under ultrasound guidance by skilled radiologists. "Fine" or "thin" (22- to 27-gauge) needles; most commonly 25-gauge needle were used under strict aseptic conditions. Although many patients had multiple nodules, yet we applied USE for the most suspicious ones only.

Aspirated fluid or cells was sent for cytological evaluation at the main laboratory of king abdulaziz university hospital. Results of FNAC were correlated with those of elastography results.

\subsection{Statistical Analysis}

Demographic patients data including their age and sex associated with detailed US \& Doppler criteria of the thyroid nodules were collected and correlated with cytological results of cases subjected to FNAC.

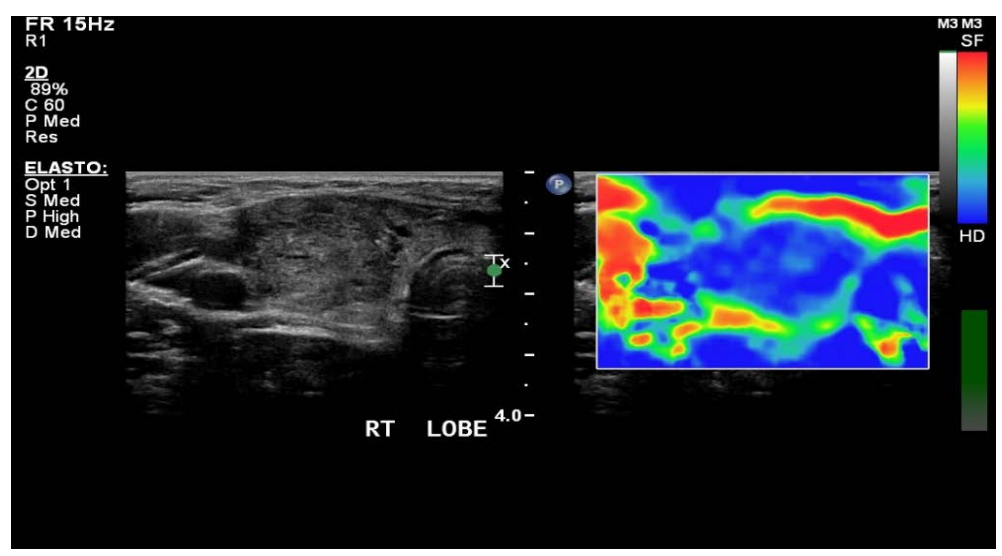

Figure 1. Real time ultrasound for 19 years old male with medullary carcinoma (blue color which is the hardest region) confirmed by FNA cytology.

Table 1. Ei Ueno classification system (2006).

\section{Benign}

Score 1 Entire area is evenly shaded green, as is surrounding tissue

Score 2 Lesion area shows mosaic color of green ,blue, and red

\section{Intermediate}

Score 3 Central part of the area is blue (stiff) and peripheral part is green (soft)

\section{Malignant}

Score $4 \quad$ Entire area is blue (stiff)

Score 5 Entire area and its surrounding area are blue (stiff) 
Statistical analyses were performed using the IBM SPSS Statistics version 21.0 (IBM Company, New York, USA) software package. Frequency tables were analyzed using the Chi-square test (X2). To assess the diagnostic value (sensitivity and specificity) of ultrasound elastography compared with the cytological results, crosstabulation tests were performed.

\section{Result}

\subsection{FNA Cytology}

The cytological diagnosis served as the reference standard for comparison with ultrasound elastography results.

Fine needle aspiration cytology (FNAC) was performed in all nodules (100) included in the study. The results of FNAC showed 22 patients (22/100 nodules, 22\%) still had inadequate cytological specimens, and were excluded from further analysis. Inadequate samples were significantly more common for "small nodules" ( $<10 \mathrm{~mm}$ in diameter). Thus a total of 100 nodules with valid cytological specimens were obtained from 78 patients (69 females, 9 males).

Fine needle aspiration (FNAC) of 78 cases, showed 16 (21\%) had a final diagnosis of malignancy (Table 2). A diagnosis of carcinoma was cytological confirmed):

7 papillary, 5 follicular, 3 medullary, and 1 hurthle cell carcinomas. The remaining 62 (79\%) were all benign nodules (Table 3). Most malignant tumors were found in the age group (26 - 35 years), and females were more affected than males. The distribution of different types of pathologically confirmed malignant nodules in correlation to the patients' age groups and gender was demonstrated in Table 3.

\subsection{Ultrasound Result}

Thyroid ultrasound (US) features associated with malignancy in thyroid nodules are microcalcifications, hypoechogenicity, irregular margins or absent halo sign, solid aspect, intranodular vascularization, and shape ratio $(\mathrm{A} / \mathrm{T} \geq 1)$. These patterns, taken singly, are poorly predictive (Table 4).

Our results showed nodule hypoechogenicity pattern (sensitivity $62 \%$ and specificity $82 \%$ ) was the US pattern most predictive of malignancy. The absent halo sign had sensitivity $0 \%$ and specificity 82 ), while spot mi-

Table 2. Fine needle aspiration biopsy results in 78 patients with thyroid nodules.

\begin{tabular}{ccccc}
\hline & & Frequency & Percent & Cumulative percent \\
\hline \multirow{3}{*}{ Valid } & M & 16 & 16 & 16.0 \\
& B & 62 & 62 & 78.0 \\
& Missing & 22 & 22 & 100.0 \\
\hline
\end{tabular}

Table 3. Distribution of different types of pathologically confirmed malignant nodules in correlation to the patients' age groups and gender.

\begin{tabular}{|c|c|c|c|c|c|c|}
\hline \multirow{2}{*}{ Age group } & \multicolumn{2}{|c|}{ Sex } & \multicolumn{4}{|c|}{ Types of maligenancy } \\
\hline & $\mathrm{F}$ & M & Medullary & Papillary & Follicular neoplasm & Hurthle \\
\hline $0-25$ & 1 & 1 & 1 & 1 & 0 & 0 \\
\hline $26-35$ & 5 & 0 & 1 & 3 & 1 & 0 \\
\hline $36-45$ & 1 & 1 & 0 & 1 & 1 & 0 \\
\hline $46-55$ & 3 & 1 & 1 & 0 & 2 & 1 \\
\hline$>56$ & 1 & 2 & 0 & 2 & 1 & \\
\hline \multirow[t]{2}{*}{ Total } & 11 & 5 & 3 & 7 & 5 & 1 \\
\hline & \multicolumn{2}{|c|}{16} & \multicolumn{4}{|c|}{16} \\
\hline
\end{tabular}


crocalcifications feature produced sensitivity $44 \%$ and specificity $92 \%$. The pattern of intranodular blood flow, taken alone, was not predictive of malignancy (sensitivity $69 \%$ and specificity $77 \%$ ). Height to width ratio $>1$ produced sensitivity $75 \%$ and specificity $83 \%$ respectively, and blurred margin showed $18.7 \%$ sensitivity and $97 \%$ specificity for malignancy (Table 4).

According to our results the highest positive predictive value was for hypoechogenicity and nodular shape ratio $(\mathrm{A} / \mathrm{P}>1)$. The combination of echographic patterns all together will be most predictive of US for detection of malignancy to FNAC. They showed increased ultrasound sensitivity and specificity to $75 \%$ and $75.8 \%$ respectively with a negative predictive value of $82.2 \%$ and positive predictive value of $44 \%$ and accuracy of $75.6 \%$ (Table 5).

\subsection{Ultrasound Elastography (USE) Result}

Fine needle aspiration (FNA) reveals sixteen nodules were malignant and 62 were benign. Correlation of FNAB results to those of USE showed that the sensitivity and specificity of the US-elastography for thyroid cancer diagnosis were $93.7 \%$ and $90 \%$ ), respectively. The positive and negative predictive values were $71 \%$ and $98 \%$, respectively. The accuracy of the technique was $91 \%$. The p value was significant $(0.000)$ (Table 6).

This study reported that USE scores of 1 or 2 were found in 47 cases and were diagnosed as benign lesions, which was $100 \%$ confirmed by FNAB. A score of 3 was found in 12 cases with two cases of malignant (follicular carcinoma), and 10 were benign lesions. Nineteen cases had scores of 4 and 5. FNAB confirmed malignancy in thirteen cases, and 6 benign lesions as shown in Table 7. This produces a sensitivity of $87 \%$ and a specificity of $90 \%$ for USE scores 4 and 5 being predictive of malignancy.

Table 4. Predictivity of thyroid ultrasound features for the identification of malignant thyroid nodules.

\begin{tabular}{|c|c|c|c|c|c|c|c|}
\hline Feature & Beni & & Malignant $(n=16)$ & Sensitivity \% & Specificity \% & PPV \% & NPV \% \\
\hline \multirow{2}{*}{ Hypoechogenicity } & Present & 11 & 10 & & & & \\
\hline & Absent & 51 & 6 & 62 & 82 & 47 & 89 \\
\hline \multirow{2}{*}{ Halo sign } & Present & 11 & 0 & & & & \\
\hline & Absent & 51 & 16 & 0 & 82 & 0 & 76 \\
\hline \multirow{2}{*}{ microcalcifications } & Present & 5 & 7 & & & & \\
\hline & Absent & 57 & 9 & 44 & 92 & 58 & 77 \\
\hline \multirow{2}{*}{$\begin{array}{l}\text { Intranodular blood } \\
\text { flow }\end{array}$} & Present & 15 & 11 & 69 & 77 & 42 & 90 \\
\hline & Absent & 47 & 5 & & & & \\
\hline \multirow{2}{*}{$\mathrm{A} / \mathrm{T} \geq 1$} & Present & 10 & 12 & & & & \\
\hline & Absent & 52 & 4 & 75 & 83 & 54 & 90 \\
\hline \multirow{2}{*}{ Blurred margins } & Present & 2 & 3 & & & & \\
\hline & Absent & 62 & 13 & 18.7 & 97 & 60 & 82.2 \\
\hline
\end{tabular}

Table 5. Predictivity of thyroid ultrasound features combination for the identification of malignant thyroid nodules. M: Malignant (Present). B: Benign (Absent).

\begin{tabular}{|c|c|c|c|c|c|c|c|c|}
\hline & & \multicolumn{2}{|c|}{ FNA } & \multirow{2}{*}{ Sensitivity \% } & \multirow{2}{*}{ Specificity \% } & \multirow{2}{*}{ PPV \% } & \multirow{2}{*}{ NPV \% } & \multirow{2}{*}{ PV } \\
\hline & & M & B & & & & & \\
\hline \multirow{3}{*}{$\begin{array}{c}\text { US } \\
\text { Result }\end{array}$} & Present M & 12 & 15 & 75 & 75.8 & 44.4 & 82.2 & 0.007 \\
\hline & Absent B & 4 & 47 & & & & & \\
\hline & & 16 & 62 & & & & & \\
\hline
\end{tabular}


Table 6. Predictivity of ultrasound elastography in patients with thyroid nodules that were confirmed to be benign (B) or malignant (M) on cytology.

\begin{tabular}{|c|c|c|c|c|c|c|c|c|}
\hline & & \multicolumn{2}{|c|}{ FNA } & \multirow{2}{*}{$\begin{array}{c}\text { Sensitivity } \\
\%\end{array}$} & \multirow{2}{*}{$\begin{array}{c}\text { Specificity } \\
\%\end{array}$} & \multirow{2}{*}{$\begin{array}{c}\text { PPV } \\
\%\end{array}$} & \multirow{2}{*}{$\begin{array}{c}\text { NPV } \\
\%\end{array}$} & \multirow{2}{*}{$\mathrm{Pv}$} \\
\hline & & M & B & & & & & \\
\hline \multirow{2}{*}{ Elasto result } & Present & 15 & 6 & 93.7 & 90 & 71 & 98 & 0.000 \\
\hline & Absent & 1 & 56 & & & & & \\
\hline \multicolumn{2}{|c|}{ Total } & 16 & 62 & & & & & \\
\hline
\end{tabular}

Table 7. Results of FNAB in correlation to USE scoring system.

\begin{tabular}{|c|c|c|c|}
\hline FNA & No. of benign & No. of malignant & Total no. \\
\hline Score 1 & 14 & 0 & 14 \\
\hline Score 2 & 33 & 0 & 33 \\
\hline Score 3 & 10 & 2 & 12 \\
\hline Score 4 & 3 & 8 & 11 \\
\hline Score 5 & 2 & 6 & 8 \\
\hline Total no. & 62 & 16 & 78 \\
\hline
\end{tabular}

\section{Discussion}

The aims of our prospective study were to evaluate the elastographic appearances of thyroid nodules and to determine whether ultrasound elastography (USE) may assist in differentiating benign from malignant thyroid nodules and results in reducing of thyroid biopsies.

Thyroid cancers have a harder consistency than benign thyroid nodules; therefore, RTE has been recently proposed as a new diagnostic tool able to differentiate malignant from benign lesions by providing an estimation of tissue stiffness [20] [22] [23].

In a recent meta analysis, including 639 unselected thyroid nodules, real time elastography (RTE) accomplished with a sensitivity of $92 \%$ and a specificity of $90 \%$ in discriminating malignant from benign lesions, although a significant heterogeneity for specificity of the different reports was found [24]. Moreover, Rago et al. [25], in a very recent study, confirmed the effectiveness of RTE also in the presurgical selection of thyroid nodules with indeterminate or not diagnostic cytology. Indeed, RTE evaluation displayed effective PPV and NPV (76.9\% and 99.0\%, respectively) with excellent accuracy (92.9\%) [24]. Rago et al. [26] recently published a study of real-time ultrasound elastography in 96 consecutive patients with a solitary thyroid nodule undergoing surgery for compressive symptoms or suspicion of malignancy on prior fine-needle aspiration biopsy. Tissue stiffness was scored from 1 to 5 based on subjective analysis of the elastogram image. They reported that scores of 1 or 2 were found in 49 cases-all benign lesions. A score of 3 was found in thirteen cases with one case of carcinoma, and twelve from benign lesions. Thirty cases had scores of 4 or 5 , and all were carcinomas. They reported a sensitivity of $97 \%$ and a specificity of $100 \%$ for a score of 4 or 5 being predictive of malignancy.

In our study, tissue stiffness on ultrasound elastography was scored from 1 (greatest elastic strain) to 5 (no strain) based on subjective analysis of the elastogram image. The scoring was classified to differentiate benign and malignant lesions and is based on color pattern with elastography image. Score 1, and 2 included nodules with high elasticity, score 3 was maintained as an intermediate score; and scores 4 and 5 included nodules with low elasticity. Using this score classification, the predictivity of US elastography was highly rewarding. Scores 4 and 5 were associated with malignancy with sensitivity of $87 \%$, specificity of $90 \%$, a PPV of $68 \%$, and an NPV of $90 \%$.

Much more rewarding were the negative predictive values of the pattern of high elasticity scores 1 , and 2 to exclude malignancy. In the current study, reported that scores of 1 or 2 were found in 47 cases, all benign lesions diagnosis at cytology. This means that nodules with high elasticity, which represent the largest proportion of 
nodules with indeterminate cytology, have no probability to bear malignancy (according to our study result. The low number of false-negative results at USE, together with the low progression rate of differentiated thyroid cancer, would allow most patients to be placed in follow-up without significant costs in terms of prognosis. A score 3 (intermediate score) was found in 12 cases with two cases of carcinomas, and 10 cases benign lesions. In score 3 according to our result, all patients with score 3 must be sent to fine needle aspiration cytology (FNAC) for confirmation. Thus, by combining the scores 1, 2, 3, 4, and 5, ultrasound elastography (USE) had a sensitivity of $93.7 \%$, a specificity of $92 \%$, a positive predictive value of $72 \%$, a negative predictive value of $98.0 \%$, and an accuracy of $90.1 \%$ in the prediction of malignancy. Our results are very close to the findings reported by previous studies [24] [27], showing RTE sensitivity of 92\% and specificity of 93.7\% (considering Elastography Score 1 and 2 as benign and Elastography Score 4 and 5 as malignant).

In summary, we found that USE is an easy, non-invasive and rapid technique that can be used routinely in thyroid US scans to select cases for FNAB, and decrease the number of unnecessary biopsies, and consequently decrease its hazards and costs. Cases that show score 1 or 2 are not in need for further investigation, and only follow up should be recommended. Cases with score 4 or 5 are considered to be highly malignant and other US criteria of malignancy should be looked for to support the diagnosis e.g. pattern of vascularity and cervical lymph nodes infiltration. FNAB should be recommended in all cases of score 3 where malignancy can't be excluded using USE criteria only.

Most studies show an incidence of malignancy of $2 \%-5 \%$ in nodules selected for biopsy, and the incidence of malignancy is much lower in all unselected nodules [28].

In the current study, all the100 nodules selected for biopsy by the real-time ultrasound, the cytology results showed the incidence of malignancy was (15\%). This study shows much higher prevalence of malignancy compared with previous reports.

Malignant nodules were significantly smaller in diameter than benign (1.91.0 vs. $2.71 .7 \mathrm{~cm})$, in apparent disagreement with previous studies reporting a higher prevalence of cancer in nodules larger than $4 \mathrm{~cm}$ [27] [29]. However, by analyzing the possible relationship between size and cancer in a large series of nodules with indeterminate or suspected cytology, the lowest likelihood of malignancy was observed in lesions of $2.5 \mathrm{~cm}$, the risk increasing either in smaller (53\% per centimetre decrease in size) or in larger nodules (39\% per centimeter increase in size) [30]. Moreover, a higher prevalence of cancer in nodules with smaller size has been recently described (26\% of tumors smaller than $1 \mathrm{~cm}$ ) [27].

In our study, ultrasound elastograms predicted malignancy with $87.5 \%$ sensitivity and $90 \%$ specificity, $70 \%$ positive predictive value and $96.5 \%$ negative predictive in nodules that had a greatest diameter of $1 \mathrm{~cm}$ or more. 14 nodules of 16 of the total nodules proven by the FNA had a greatest diameter of $1 \mathrm{~cm}$ or more $(1.1-2.0 \mathrm{~cm})$. The remaining 2 nodules were less than $1 \mathrm{~cm}$ in size. This results match with the previous report mentioned above. However there was no relationship between the ultrasound elastography and the size of the nodule.

Our study limitations. First, although the ultrasound exams, ultrasound guided fine needle aspiration and elastography had been done by more than three radiologists, reflecting the expected difference between readers definitely exists in clinical practice. There was no significant differences (almost the same) between the examiners in their reading results for ultrasound examinations. But elastography results comparatively showed slight differences between the examiners, this may be because the elastography is an operator dependant technique and the fact that there were different radiologists who involved in this study to obtain the elastography images. This type of elastography procedure which is depending on personal color scale to be replaced by the other elastography techniques appear more independent operator and quantitative analysis of nodule stiffness to improve the real time elastography such as shear wave elastography.

Our study supported by previous studies reported that Different methods have been proposed for the quantitative analysis of elastographic images, such as off-line processing of strain images by strain index [31] [32], carotid artery pulsation [33] [34], and shear wave elastography [29]. These techniques appear more operators independent and reproducible; although most of them are currently limited in clinical practice (too time consuming for the calculation of nodule stiffness and weak utility in case of multinodular goiter). Recently, however, shear wave elastography has shown a valuable PPV (92.3\%) in the presurgical diagnosis of malignant lesions in a large series of unselected thyroid nodules, also in case of multinodular goiter [29].

Second, the previous study reported that, the major limitation of FNA cytology is that $10 \%$ to $15 \%$ of specimens are nondiagnostic [35], and $10 \%$ to $20 \%$ are indeterminate [26] [28] [36]. Our study percentage of nodule specimens with insufficient or inadequate for diagnosis at US-FNAC was $22 \%$. This percentage is higher than 
the percentage of inadequate cytology have been previously reported above. These insufficient specimens were excluded could affect the result of elastography by reducing the number of nodules enrolled in the study, because FNA was used as a reference standard.

\section{Conclusions}

Ultrasound elastography is a promising imaging technique that is useful in the differential diagnosis of thyroid cancer. Further improvements in the technique and the diagnostic criteria are necessary for this examination to provide a useful contribution to diagnosis.

The use of ultrasound elastography would lead to low thyroid biopsies because of the high elasticity of being strongly associated with a benign cytology. There will be a need for additional studies on large population with thyroid nodules to determine if it has adequate technical sensitivity and predictive value in order to avoid the need for a biopsy.

\section{Acknowledgements}

This project was funded by Deanship of Scientific Research (DSR) King Abdulaziz University, Jeddah, under grant no. (371/142/1432). The authors, therefore, acknowledge with thanks DSR technical and finical support.

\section{References}

[1] Cooper, D.S., Doherty, G.M., Haugen, B.R., Kloos, R.T., Lee, S.L., Mande, S.J., Mazzaferri, E.L., McIver, B., Pacini, F., Schlumberger, M., Sherman, S.I., Steward, D.L. and Tuttle, R.M. (2009) American Thyroid Association (ATA) Guidelines Taskforce on Thyroid Nodules and Differentiated Thyroid Cancer. Revised American Thyroid Association Management Guidelines for Patients with Thyroid Nodules and Differentiated Thyroid Cancer. Thyroid, 19, 1167-1214. http://dx.doi.org/10.1089/thy.2009.0110

[2] Gharib, H., Papini, E., Paschke, R., Duick, D.S., Valcavi, R., Hegedus, L. and Vitti, P. (2010) AACE/AME/ETA Task Force on Thyroid Nodules 2010 American Association of Clinical Endocrinologists, Associazione Medici Endocrinologi, and European Thyroid Association Medical Guidelines for Clinical Practice for the Diagnosis and Management of Thyroid Nodules. Endocrine Practice, 16, 468-475.

[3] Gharib, H., Papini, E. and Paschke, R. (2008) Thyroid Nodules: A Review of Current Guidelines, Practices, and Prospects. European Journal of Endocrinology, 159, 493-505. http://dx.doi.org/10.1530/EJE-08-0135

[4] Rago, T., Chiovato, L., Aghini-Lombardi, F., Grasso, L., Pinchera, A. and Vitti, P. (2001) Non-Palpable Thyroid Nodules in a Borderline Iodine-Sufficient Area: Detection by Ultrasonography and Follow-Up. Journal of Endocrinological Investigation, 24, 770-776.

[5] Aghini-Lombardi, F., Antonangeli, L., Martino, E., Vitti, P., Maccherini, D., Leoli, F., Rago, T., Grasso, L., Valeriano, R., Balestrieri, A. and Pinchera, A. (1999) The Spectrum of Thyroid Disorders in an Iodine-Deficient Community: The Pescopagano Survey. Journal of Clinical Endocrinology \& Metabolism, 84, 561-566. http://dx.doi.org/10.1210/jc.84.2.561

[6] Castro, M.R. and Gharib, H. (2003) Thyroid Fine-Needle Aspiration Biopsy: Progress, Practice, and Pitfalls. Endocrine Practice, 9, 128-136. http://dx.doi.org/10.4158/EP.9.2.128

[7] Mandel, S.J. (2004) A 64-Year-Old Woman with a Thyroid Nodule. JAMA, 292, 2632-2642. http://dx.doi.org/10.1001/jama.292.21.2632

[8] Castro, M.R. and Gharib, H. (2005) Continuing Controversies in the Management of Thyroid Nodules. Annals of Internal Medicine, 142, 926-931. http://dx.doi.org/10.7326/0003-4819-142-11-200506070-00011

[9] Mazzaferri, E.L. (1993) Management of Solitary Thyroid Nodule. New England Journal of Medicine, 328, 553-559. http://dx.doi.org/10.1056/NEJM199302253280807

[10] Hegedus, L. (2004) The Thyroid Nodule. New England Journal of Medicine, 351, 1764-1771. http://dx.doi.org/10.1056/NEJMcp031436

[11] Tan, G.H. and Gharib, H. (1997) Thyroid Incidentalomas: Management Approaches to Non-Palpable Nodules Discovered Incidentally on Thyroid Imaging. Annals of Internal Medicine, 126, 226-231. http://dx.doi.org/10.7326/0003-4819-126-3-199702010-00009

[12] Danese, D., Sciacchitano, S., Farsetti, A., Andreoli, M. and Pontecorvi, A. (1998) Diagnostic Accuracy of Conventional versus Sonography-Guided Fine Needle Aspiration Biopsy of Thyroid Nodules. Thyroid, 8, 15-21. http://dx.doi.org/10.1089/thy.1998.8.15

[13] Carmeci, C., Jeffrey, R.B., McDougall, I.R., Nowels, K.W. and Weigel, R.J. (1998) Ultrasound-Guided Fine-Needle 
Aspiration Biopsy of Thyroid Masses. Thyroid, 8, 283-289. http://dx.doi.org/10.1089/thy.1998.8.283

[14] Lerner, R.M., Huang, S.R. and Parker, K.J. (1990) Sonoelasticity Images Derived from Ultrasound Signals in Mechanically Vibrated Tissues. Ultrasound in Medicine and Biology, 16, 231-239. http://dx.doi.org/10.1016/0301-5629(90)90002-T

[15] Ophir, J., Alam, S.K., Garra, B., Kallel, F., Knofagou, E., Krouskop, T. and Varghese, T. (1999) Elastography: Ultrasonic Estimation and Imaging of the Elastic Properties of Tissues. Proceedings of the Institution of Mechanical Engineers, 213, 203-233. http://dx.doi.org/10.1243/0954411991534933

[16] Garra, B.S., Cespedes, E.I., Ophir, J., Spratta, S.R., Zuurbier, R.A., Magnant, C.M. and Pennaren, M.F. (1997) Elastography of Breast Lesions: Initial Clinical Results. Radiology, 202, 79-86.

[17] Cochlin, D.L., Ganatra, R.H. and Griffiths, D.F. (2002) Elastography in the Detection of Prostatic Cancer. Clinical Radiology, 57, 1014-1020. http://dx.doi.org/10.1053/crad.2002.0989

[18] Janssen, J., Schlörer, E. and Greiner, L. (2007) EUS Elastography of the Pancreas: Feasibility and Pattern Description of the Normal Pancreas, Chronic Pancreatitis, and Focal Pancreatic Lesions. Gastrointestinal Endoscopy, 65, 971-978. http://dx.doi.org/10.1016/j.gie.2006.12.057

[19] Tanaka, K., Fukunari, N., Igarashi, Y., et al. (2006) Evaluation of Thyroid Malignancy Using Real-Time Tissue Elastography. European Radiology, 16, 547.

[20] Rago, T., Santini, F., Scutari, M., Pinchera, A. and Vitti, P. (2007) Elastography: New Developments in Ultrasound for Predicting Malignancy in Thyroid Nodules. Journal of Clinical Endocrinology \& Metabolism, 92, 2917-2922. http://dx.doi.org/10.1210/jc.2007-0641

[21] Itoh, A., Ueno, E., Tohno, E., Kamma, H., Takahashi, H., Shiina, T., Yamakawa, M. and Matsumura, T. (2006) Breast Disease: Clinical Application of US Elastography for Diagnosis. Radiology, 239, 341-350. http://dx.doi.org/10.1148/radiol.2391041676

[22] Asteria, C., Giovanardi, A., Pizzocaro, A., Cozzaglio, L., Morabito, A., Somalvico, F. and Zoppo, A. (2008) US-Elastosonography in the Differential Diagnosis of Benign and Malignant Thyroid Nodules. Thyroid, 18, 523-531. http://dx.doi.org/10.1089/thy.2007.0323 22

[23] Rago, T., Fiore, E., Scutari, M., Santini, F., Di Coscio, G., Romani, R., Piaggi, P., Ugolini, C., Basolo, F., Miccoli, P., Pinchera, A. and Vitti, P. (2010) Male Sex, Single Nodularity, and Young Age Are Associated with the Risk of Finding a Papillary Thyroid Cancer on Fine Needle Aspiration Cytology in a Large Series of Patients with Nodular Thyroid Disease. European Journal of Endocrinology, 162, 763-770. http://dx.doi.org/10.1530/EJE-09-0895

[24] Rago, T., Scutari, M., Santini, F., Loiacono, V., Piaggi, P., Di Coscio, G., Basolo, F., Berti, P., Pinchera, A. and Vitti, P. (2010) Real-Time Elastosonography: Useful Tool for Refining the Presurgical Diagnosis in Thyroid Nodules with Indeterminate or Nondiagnostic Cytology. The Journal of Clinical Endocrinology \& Metabolism, 95, 5274-5280. http://dx.doi.org/10.1210/jc.2010-0901

[25] Bojunga, J., Herrmann, E., Meyer, G., Weber, S., Zeuzem, S. and Friedrich-Rust, M. (2010) Real-Time Elastography for the Differentiation of Benign and Malignant Thyroid Nodules: A Meta-Analysis. Thyroid, 20, 1145-1150. http://dx.doi.org/10.1089/thy.2010.0079

[26] Rago, T., Di Coscio, G., Ugolini, C., Scutari, M., Basolo, F., Latrofa, F., Romani, R., Berti, P., Grasso, L., Braverman, L.E., Pinchera, A. and Vitti, P. (2007) Clinical Features of Thyroid Autoimmunity Are Associated with Thyroiditis on Histology and Are Not Predictive of Malignancy in 570 Patients with Indeterminate Lesions on Cytology Who Had a Thyroidectomy. Clinical Endocrinology, 67, 363-369. http://dx.doi.org/10.1111/j.1365-2265.2007.02892.x

[27] Rausei, S., Dionigi, G., Frattini, F., Castano, P., Leotta, A., Rovera, F., Boni, L., Bartalena, L. and Dionigi, R. (2011) Nodule Size and Fine-Needle Aspiration Biopsy: Diagnostic Challenges for Thyroid Malignancy. The American Journal of Surgery, 201, 525-530. http://dx.doi.org/10.1016/j.amjsurg.2010.03.008

[28] Rago, T., Di Coscio, G., Basolo, F., Scutari, M., Elisei, R., Berti, P., Miccoli, P., Romani, R., Faviana, P., Pinchera, A. and Vitti, P. (2007) Combined Clinical, Thyroid Ultrasound and Cytological Features Help to Predict Thyroid Malignancy in Follicular and Hurthle Cell Thyroid Lesions: Results from a Series of 505 Consecutive Patients. Clinical Endocrinology, 66, 13-20.

[29] Sebag, F., Vaillant-Lombard, J., Berbis, J., Griset, V., Henry, J.F., Petit, P. and Oliver, C. (2010) Shear Wave Elastography: A New Ultrasound Imaging Mode for the Differential Diagnosis of Benign and Malignant Thyroid Nodules. The Journal of Clinical Endocrinology \& Metabolism, 95, 5281-5288. http://dx.doi.org/10.1210/jc.2010-0766

[30] Marohn, M.R., Clark, D.P., Umbricht, C.B. and Zeiger, M.A. (2008) A Diagnostic Predictor Model for Indeterminate or Suspicious Thyroid FNA Samples. Thyroid, 18, 933-941. http://dx.doi.org/10.1089/thy.2008.0108

[31] Lyshchik, A., Higashi, T., Asato, R., Tanaka, S., Ito, J., Mai, J.J., Pellot-Barakat, C., Insana, M.F., Brill, A.B., Saga, T., Hiraoka, M. and Togashi, K. (2005) Thyroid Gland Tumor Diagnosis at US Elastography. Radiology, 237, 202-211. http://dx.doi.org/10.1148/radiol.2363041248 
[32] Vorländer, C., Wolff, J., Saalabian, S., Lienenlüke, R.H. and Wahl, R.A. (2010) Real-Time Ultrasound ElastographyA Noninvasive Diagnostic Procedure for Evaluating Dominant Thyroid Nodules. Langenbeck's Archives of Surgery, 395, 865-871. http://dx.doi.org/10.1007/s00423-010-0685-3

[33] Dighe, M., Bae, U., Richardson, M.L., Dubinsky, T.J., Minoshima, S. and Kim, Y. (2008) Differential Diagnosis of Thyroid Nodules with US Elastography Using Carotid Artery Pulsation. Radiology, 248, 662-669. http://dx.doi.org/10.1148/radiol.2482071758

[34] Luo, S., Kim, E.H., Dighe, M. and Kim, Y. (2011) Thyroid Nodule Classification Using Ultrasound Elastography via Linear Discriminant Analysis. Ultrasonics, 51, 425-431. http://dx.doi.org/10.1016/j.ultras.2010.11.008

[35] Redman, R., Zalaznick, H., Mazzaferri, E.L. and Massoll, N.A. (2006) The Impact of Assessing Specimen Adequacy and Number of Needle Passes for Fine-Needle Aspiration Biopsy of Thyroid Nodules. Thyroid, 16, 55-60. http://dx.doi.org/10.1089/thy.2006.16.55

[36] Gharib, H. and Papini, E. (2007) Thyroid Nodules: Clinical Importance, Assessment, and Treatment. Endocrinology and Metabolism Clinics of North America, 36, 707-735. http://dx.doi.org/10.1016/j.ecl.2007.04.009 